\title{
The Effects of Teat Bar Design and Weaning Method on Behavior, Intake, and Gain of Dairy Calves
}

\author{
P. P. Nielsen, ${ }^{\star 1}$ M. B. Jensen, $†$ and L. Lidfors ${ }^{\star}$ \\ *Department of Animal Environment and Health, Swedish University of Agricultural Sciences, PO Box 234, SE-532 23 Skara, Sweden \\ †Department of Animal Health, Welfare and Nutrition, Faculty of Agricultural Sciences, University of Aarhus, PO Box 50, DK-8830 Tjele, \\ Denmark
}

\section{ABSTRACT}

The aim of the present study was to investigate the effects of teat-feeding method and weaning method on behavior, milk and concentrate intake, and weight gain of group-housed dairy calves. Forty-eight calves were housed in groups of 4 and offered $6 \mathrm{~L}$ of whole milk per calf in 2 daily feedings. In 6 of the 12 group pens, the calves were offered the milk in a teat bar with a separate milk compartment for each teat, whereas in the remaining 6 pens, the calves were offered the milk in a teat bar with all teats connecting to 1 shared milk compartment. Calves were gradually weaned off milk by reducing the volume of milk over a 10 -d period, starting at an average age of $47 \mathrm{~d}$. In 6 pens ( 3 pens with each of the 2 milk-feeding treatments), calves were weaned by volume reduction, whereas in the remaining pens, the calves were weaned by diluting the milk with water (WD) and maintaining the same total volume of liquid. Daily concentrate intake per pen was recorded during weaning and $1 \mathrm{wk}$ after weaning. Behavior was recorded around milk feeding, by direct observation on 1 occasion before and on 1 occasion during weaning, and by video on 1 occasion before and 2 occasions during weaning. Furthermore, the behavior was recorded during the $15 \mathrm{~h}$ of light on 1 occasion during weaning. Individual milk intake was measured twice by weighing the calves immediately before and after milk feeding. The calves fed via a separate teat bar switched between teats more often than calves fed with a shared teat bar. There was greater variation in the duration of ingesting milk within groups fed via a separate teat bar, but no effect of teat bar design was found on the variation in milk intake within the groups. Calves fed via a separate teat bar took longer to start eating concentrate after milk feeding than calves fed with a shared teat bar. The WD calves had a lower concentrate intake during weaning than weaned by volume reduction calves. The

Received September 4, 2007.

Accepted January 15, 2008.

${ }^{1}$ Corresponding author: per.peetz.nielsen@hmh.slu.se
WD calves were lying down less during the 30 min after milk feeding and during the $15 \mathrm{~h}$ of light, although they had a shorter latency to lie down after milk feeding. In conclusion, a separate teat bar increased teat switching, increased variation in duration of ingesting milk, and increased the latency to eat concentrates after milk feeding. There was no effect of the teat bar design on feed intake or weight gain. However, weaning the calves by gradually diluting the milk with water reduced lying during weaning and reduced the concentrate intake during and after weaning.

Key words: calf, behavior, competition, milk-feeding method

\section{INTRODUCTION}

An increasing number of farmers house their calves in groups during the milk-feeding period and thus allow them to perform normal social behavior. However, when housed in a group, calves compete for the milk, and offering the milk in open buckets or a large trough offers no protection from this competition. When calves are offered the milk in teat buckets, they take longer to ingest the milk, they suck on the teats after milk ingestion, and they perform less cross-sucking (Jensen and Budde, 2006). However, calves have a natural tendency to switch from one teat to another when the milk flow is low or stops (de Passillé and Rushen, 2006), and group-housed calves compete for milk even if they are fed via a teat (Jensen and Budde, 2006). A modification of the individual teat bucket is a larger milk compartment with several teats for group-housed calves, a socalled teat bar. If the teat bar has a separate milk compartment for each teat, this corresponds in principle to individual teat buckets. Separate compartments are meant to ensure that all calves ingest an equal amount of milk, but the calves may not empty the compartments at the same time, and therefore, teat switching and milk stealing may occur. If the teat bar has a shared milk compartment for all teats, all the calves finish ingesting milk at the same time, and the amount of teat switching may be reduced. This may also reduce 
cross-sucking, which is a redirection of the sucking behavior toward the head or body of another calf (de Passillé and Rushen, 1997). However, using a teat bar with a shared milk compartment does not ensure that all calves get the same amount of milk, because some calves may be able to ingest the milk faster than others, and a high variation in age within the group may increase the competition between calves.

Previous findings have shown that gradual weaning reduces the occurrence of cross-sucking both during and after weaning as compared with abrupt weaning (Nielsen et al., 2008). Another study, however, has shown that gradual weaning increases the occurrence of crosssucking (Jung and Lidfors, 2001), probably because small portions of milk stimulate the sucking motivation (Rushen and de Passillé, 1995) but do not provide a sufficient outlet for the sucking motivation. Therefore, increasing the volume by diluting the milk with water may be a solution to this problem (de Passillé et al., 2004; Jasper et al., 2007). Keil and Langhans (2001) found that the total energy intake influences development of cross-sucking during the weaning period, and gradual weaning over $14 \mathrm{~d}$ has been shown to increase the concentrate intake of calves during the weaning period (Jensen, 2006; Nielsen et al., 2008) and thereby ease the transition to a solid-based feed.

To date, there has to our knowledge not been any research published addressing the effect of teat-feeding group-housed dairy calves from either shared or separate milk compartments or addressing the effect of gradually weaning calves off milk while either maintaining the volume of liquid offered by diluting with water or not on the development of cross-sucking.

The first aim of this study was to examine the effect of teat-feeding group-housed dairy calves from either a shared milk compartment or from separate milk compartments on competition for milk and cross-sucking. The second aim was to examine the effect of different weaning methods on the development of abnormal oral behaviors in dairy calves. The 2 main predictions of this study were as follows: first, that calves fed milk with a separate milk compartment teat bar would perform more teat switching and more cross-sucking compared with calves fed milk with a shared milk compartment teat bar and second, that calves weaned by reducing the volume as well as the energy of the milk would perform more cross-sucking than calves weaned by reducing the energy while maintaining the volume of milk offered.

\section{MATERIALS AND METHODS}

The experiment was conducted at the research facilities of the University of Aarhus in Foulum, Denmark,
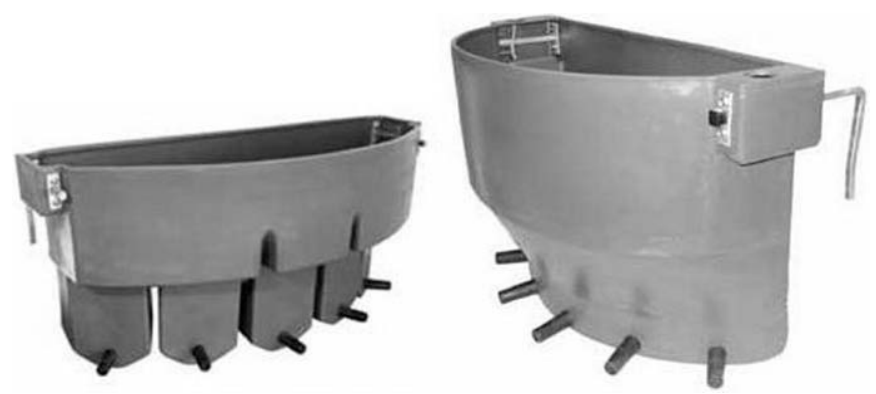

Figure 1. The types of teat bars used in this experiment. Left: a teat bar with a separate milk compartment for each teat; right: a teat bar with a shared milk compartment for all teats. Note that for this experiment, the teat bars were modified as described in the text.

during the fall of 2006. Forty-eight male and female Holstein calves ( 2 blocks of 24 calves) were separated from the dam within the first $24 \mathrm{~h}$ and housed individually in straw-bedded pens until they were moved to the experiment building at the age of $26( \pm 10) \mathrm{d}$. Within each block, the calves were ranked according to age, and 4 age groups of 6 calves of similar age were defined. Within these age groups, each calf was randomly allocated to 1 of 6 new groups to maximize the age differences, and thus the level of competition for teats, within the groups. Both male and female calves were represented in each group (4 groups with 1 male calf and 3 female calves and 8 groups with 2 male and 2 female calves). All calves received their daily milk allowance of $6 \mathrm{~L}$ of whole milk in 2 daily feedings (one at $0845 \mathrm{~h}$ and the other at $1645 \mathrm{~h}$ ) either in a teat bar with 4 teats connected to a shared compartment (Milk Bar 6, Dairy Spares Ltd., Shropshire, UK; Figure 1) or a teat bar with 4 teats connecting each to a separate compartment (Milk Bar 5, Dairy Spares Ltd.; Figure 1). The separate compartment teat bar was $830 \mathrm{~mm}$ long $\times 290$ $\mathrm{mm}$ wide $\times 370 \mathrm{~mm}$ high, and the distance from the tip of 1 teat to the tip of the neighboring teat was $18.5 \mathrm{~cm}$. The shared compartment teat bar was $700 \mathrm{~mm}$ long $\times$ $300 \mathrm{~mm}$ wide $\times 400 \mathrm{~mm}$ high, and the distance from the tip of 1 teat to the tip of a neighboring teat was $13 \mathrm{~cm}$.

In each block, 3 groups were fed using a separate teat bar, whereas 3 groups were fed with a shared teat bar. Normally the teat bars had 5 or 6 teats, but they were modified for this experiment to have only 4 teats each. Furthermore, the separate teat bars had the inner walls separating the 4 compartments extended to the top of the container to increase the volume of each compartment to accommodate at least $3 \mathrm{~L}$.

The calves in block 1 were fed the full milk allowance for $23 \mathrm{~d}$, and the calves in block 2 were fed the full milk allowance for $21 \mathrm{~d}$ before weaning was initiated. When 


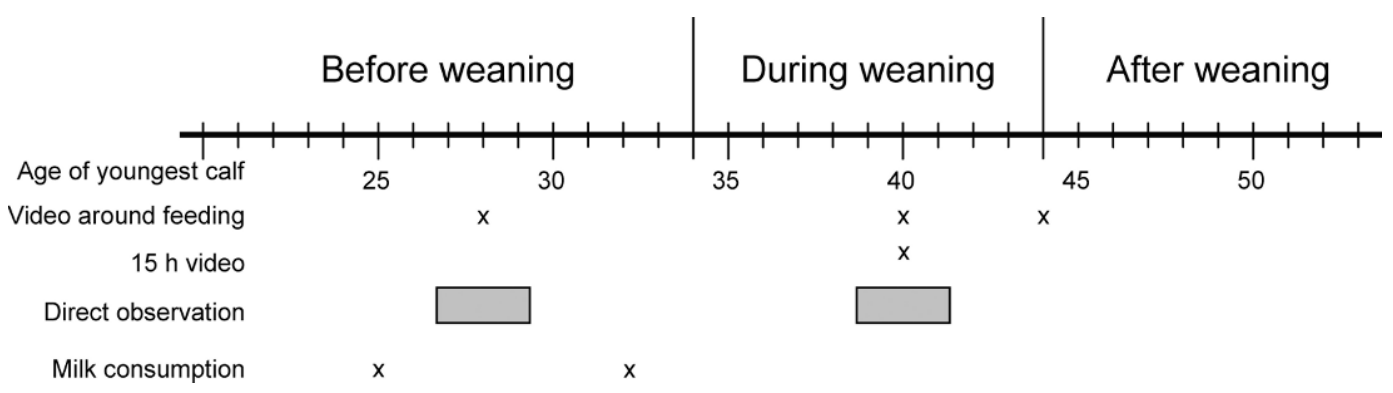

Figure 2. Time plan illustrating the occurrence of 30-min video recordings at feeding, $15 \mathrm{~h}$ of video recording, $30 \mathrm{~min}$ of direct observations at feeding, and recordings of milk consumption of the calves.

the youngest calf in each block was $35 \mathrm{~d}$ old, the calves were weaned off milk by gradually reducing the volume of milk over a 10 -d period [d 1 to $2(5 \mathrm{~L} / \mathrm{d}), \mathrm{d} 3$ to $4(4$ $\mathrm{L} / \mathrm{d})$, d 5 to $7(3 \mathrm{~L} / \mathrm{d})$, and $d 8$ to $10(2 \mathrm{~L} / \mathrm{d})$ ]. The groups in each block were randomly assigned to gradual weaning, 3 groups per weaning method, by either 1) reducing the volume of whole milk offered as indicated above (weaning by volume reduction, WVR), or 2) reducing the volume of whole milk offered as indicated above while adding water to a total daily volume of $6 \mathrm{~L}$ (weaning by dilution, WD).

During the weaning period, the calves were fed using the same type of teat bar as before weaning was initiated. All calves were fully weaned when the youngest calf in the block was $45 \mathrm{~d}$ old. An outline of the experiment and the observations are given in Figure 2.

Throughout the milk-feeding period and the weaning period, all calves were offered concentrates [Grøn Kalv Valset, Dansk Landbrugs Grovvareselskab, Copenhagen, Denmark (18\% CP, $4 \%$ fat, and 6\% fiber)] and hay ad libitum in troughs, whereas water was offered ad libitum in a water bowl.

\section{Milk-Feeding Procedure}

For the separate teat bar, $1 \mathrm{~L}$ of milk was added to each compartment before the teat bar was placed in the pen and after this the remaining $2 \mathrm{~L}$ of milk was added to each compartment. The shared teat bar was placed in the pen and immediately after the milk allowance for all 4 calves was poured into it. These procedures were followed to minimize competition and teat switching immediately after the teat bar was placed in the pen.

\section{Behavioral Observations and Video Recording}

Direct observations were performed twice, once before weaning and once during weaning while the calves were receiving $1.5 \mathrm{~L}$ of milk per meal. Two trained observers observed 2 groups (balanced for treatment) each day over $3 \mathrm{~d}$ for 30 min starting when the calves received their milk in the morning. Instantaneous sampling with 30-s interval was used, and the behaviors observed are described in Table 1. From these data, the number of times each calf switched from one teat to another teat, both while there was milk in the teats and while the teats were empty, were calculated. The teats were defined as being empty when the milk level was beneath the opening in the teat. Furthermore, for each calf, the total duration of ingesting milk and the total duration of nonnutritive sucking were calculated. The total duration of sucking was calculated as the sum of ingesting milk and nonnutritive sucking, and finally, the sum of eating solid food was calculated as the sum of eating concentrate and eating hay.

The behavior of the calves was video recorded for 4 $\mathrm{h}$ from $1 \mathrm{~h}$ before morning milk feeding and until $3 \mathrm{~h}$ after. These recordings were performed when the youngest calf in the block was $28 \mathrm{~d}$ old (during the milkfeeding treatment) and $40 \mathrm{~d}$ (midweaning) and $44 \mathrm{~d}$ old (last day of weaning; Figure 2). The behavior of the calves was recorded continuously from the video recordings during 60 min beginning when the milk was poured into the teat bar. The behavioral elements observed were start ingesting milk (defined as the calf having a teat in its mouth while there was still milk in the milk bar), teat empty (defined as there was no more milk available via the teat; the milk in the milk bar could be seen on the video recordings), as well as 4 elements described in Table 1: eating hay, eating concentrate, lying, and other. From these observations, the latencies from when the teat bar was placed in the pen until the first calf in each group was recorded as lying, eating concentrate, and eating hay, respectively, were calculated. Also, the latencies from when the teat bar was empty until the first calf in each group was recorded as lying, eating concentrate, and eating hay, respectively, were calculated. On d 40, video recording was performed from 0600 to $2100 \mathrm{~h}$, and scan sampling 
Table 1. Description of the behavioral elements observed in focal calves during direct observations 30 min after milk feeding 1 wk before weaning started and midweaning

\begin{tabular}{ll}
\hline Behavior & \multicolumn{1}{c}{ Description } \\
\hline Ingesting milk & The calf is having a teat with milk available in its mouth and is performing sucking behavior. \\
The teat number $1,2,3$, or 4 is noted (teats are numbered from the left to the right). \\
The calf is having a teat with no milk available in its mouth and is performing sucking behavior. \\
The teat number $1,2,3$, or 4 is noted (teats are numbered from the left to the right). \\
The calf is standing with its head over the concentrate trough while it is chewing. \\
Eating concentrate & The calf is standing with its head over the hay trough while it is chewing. \\
Eating hay & The calf is sucking on the fixture of the pen excluding the teats of the teat bar. \\
Sucking fixture & The calf is sucking on the ears, mouth, udder-base, prepuce, or any other body parts of another calf. \\
Cross-sucking & The sucking movements are performed with the body part in the mouth. \\
& The calf is licking on any part of the fixture of the pen. \\
Licking fixture & The calf is licking the head or body of another calf. \\
Licking calf & The calf is lying down with the legs tugged under the body or lying on the side with the legs stretched out. \\
Lying down & The calf is performing any other behavior that is not described above. \\
Other &
\end{tabular}

with 5-min intervals was performed to estimate the daily duration of lying, standing (the focal calf is standing or walking), and eating solid food (the sum of eating concentrate and eating hay as defined in Table 1) for each calf.

\section{Concentrate Intake}

The daily concentrate consumption was recorded on a group level from the day before weaning was initiated and until $7 \mathrm{~d}$ after weaning was completed. During this period, fresh concentrate was provided every morning and afternoon. Every morning, the concentrate leftovers were weighed and removed.

\section{Milk Intake}

Twice during the milk-feeding period (d 25 and 32), each calf was weighed immediately before and immediately after milk feeding on a digital scale (accuracy: 10 g) placed right outside the pen. Recordings of defecations $(\mathrm{n}=10)$ and urinations $(\mathrm{n}=0)$ were done between the 2 weighings, and $200 \mathrm{~g}$ was added to each calf's weight after milk feeding if they had defecated. The difference between the 2 weight measures was used to estimate the volume of milk ingested. Video recordings were conducted during these milk meals for subsequent measurement of the duration each calf was ingesting milk (Table 1).

\section{Weight Gain}

The animals were weighed at the start of the experiment, $3 \mathrm{~d}$ before weaning was initiated, and at the end of the experiment.

\section{Statistical Analysis}

Behavior Observations and Teat Switching. The behavioral elements recorded during direct observa- tions (including teat switching) and the elements recorded from the video recordings were analyzed using a generalized linear model in SAS 9.1 (PROC GENMOD, SAS Institute Inc., Cary, NC). The data recorded on separate days were analyzed separately. The observed data were summarized as number of times, or events, each individual animal performed each specific behavior during the observation period. The number of observations where the animal could perform any given activity was defined as number of trials (60 for direct observations, 180 for observations performed over a 15$\mathrm{h}$ period, and for the teat switching, the number of observations each calf had been observed ingesting milk or nonnutritive sucking). In the model statement, the variance was specified as events/trials. The responses represented a number between 0 and 1 and were therefore assumed to be binomially distributed, and the link function was specified as a logit function. The TYPE3 statement was used to ensure that the analysis was independent of the order in which the model statements were written. Group (1 to 12 ) was used to specify the subject in the repeated statement with an autoregressive correlation structure computing that the observations of the calves within each group were more dependent of each other than between groups. Least squares means of significant fixed effects were computed, and the CLDIFF procedure was used to compute the confidence intervals. The data were backtransformed using the formula for back-transforming logit data $[\exp (\mathrm{y}) /(1+\exp (\mathrm{y}) ;$ Olsson, 2002]. The data are presented as the percentage of times the behavioral elements were observed in relation to the number of times the behavioral elements could be performed with the respective confidence intervals.

The model for the analysis of the direct observations and the teat switching before weaning was initiated including teat bar, block, and observer. The model for the direct observations and the teat switching during the period of gradual weaning included teat bar, wean, 
teat bar $\times$ wean, block, and observer. During weaning, the number of teat switches while there was still milk left in the milk compartment was low, and therefore, a high number of observations was equal to zero. The number of calves performing teat switching was therefore calculated, and a $\chi^{2}$ test was performed on these data.

The model for the video observation during weaning included teat bar, wean, teat bar $\times$ wean, and block.

Latency. The latency from when the milk was poured into the teat bar and from when the teat bar was empty, respectively, until the first calf in the group was eating hay or concentrate and lying down, respectively, was analyzed using a variance component analysis procedure in SAS 9.1 (PROC MIXED) using the COVTEST option, which produces asymptotic standard errors. The general Satterthwaite approximation was used to calculate the correct denominator degrees of freedom. Least squares means with standard errors of significant fixed effects were computed, and the PDIFF procedure was used to display the differences of the least squares means (Littell et al., 1996). The model for the latency before weaning that was initiated included teat bar, and the model during weaning included teat bar, wean, and teat bar $\times$ wean.

Concentrate Intake, Milk Intake, and Weight Gain. Concentrate intake, daily weight gain, and milk intake were analyzed using a variance component analysis procedure in SAS 9.1 (PROC MIXED) as described above.

The model for concentrate intake both during and after weaning included day (day in weaning or day after weaning), teat bar, wean, day $\times$ teat bar, day $\times$ wean, day $\times$ teat bar $\times$ wean, and block.

Daily weight gains were calculated for the milk-feeding period and for the weaning period, and the two were analyzed separately. The model for weight gain before weaning included sex, teat bar, and sex $\times$ teat bar, and the model for weight gain for the period during weaning and after weaning included sex, teat bar, and weaning method with all interactions. The sex of the calves was used in the analysis, because it is know that sex has an influence on weight gain, and the model thus explains more of the variance in the data. The starting weight for each period and the age of the calf when the experiment started were included in the models as covariates. The variances of weight gain for the 2 teat bars and the 2 weaning methods, respectively, were analyzed using a simple F-test.

The data from the individual milk intake were sorted, and the difference in milk intake between the calves with the highest and lowest milk consumption within each group was used as input in this analysis. The model for milk intake included teat bar, test (first or second measure of milk intake), and teat bar $\times$ test. As repeated effect, the model for concentrate intake, weight gain, and milk intake included group, and the repeated effect was regarded as an autoregressive correlation structure assuming that correlation decreases with distance between observations.

\section{RESULTS}

\section{Before Weaning}

Although there was still milk available in the teat bar, the calves fed via a separate teat bar switched teats more often compared with the calves with a shared teat bar $(P<0.05$, Table 2$)$, but there was no effect of teat bar design on the number of teat switches between empty teats (Table 2). Calves fed with the shared teat bar tended to lick the fixture more than calves fed with the separate teat bar $(P<0.1$, Table 2$)$. Calves with the separate teat bar had a longer latency from when the milk was poured into the teat bars to when they started eating concentrate compared with calves with the shared teat bar $(P<0.05$, Table 3$)$. Teat bar design did not

Table 2. Main effect of milk-bar design (shared or separate milk compartments) on recorded behaviors and the frequency of teat switching ${ }^{1}$

\begin{tabular}{|c|c|c|c|c|c|c|}
\hline \multirow[b]{2}{*}{ Behavior ( $\%$ of observations) } & \multicolumn{2}{|c|}{ Separate } & \multicolumn{2}{|c|}{ Shared } & \multirow[b]{2}{*}{$\chi^{2}$} & \multirow[b]{2}{*}{$P$-value } \\
\hline & Mean & $\mathrm{CI}$ & Mean & $\mathrm{CI}$ & & \\
\hline Duration of sucking & 37.6 & 34.3 to 41.1 & 38.3 & 34.1 to 42.8 & 0.06 & NS \\
\hline Ingesting milk & 27.2 & 24.4 to 32.0 & 25.8 & 22.2 to 29.7 & 0.20 & NS \\
\hline Nonnutritive sucking & 10.2 & 8.0 to 12.9 & 12.4 & 9.2 to 16.7 & 0.87 & NS \\
\hline Eating solid feed & 8.1 & 4.6 to 13.7 & 13.0 & 9.4 to 17.7 & 2.43 & NS \\
\hline Cross-sucking & 1.8 & 1.1 to 2.8 & 1.0 & 0.4 to 2.8 & 1.26 & NS \\
\hline Licking calf & 0.9 & 0.6 to 1.8 & 0.9 & 0.6 to 1.3 & 0.20 & NS \\
\hline Licking fixture & 4.5 & 3.0 to 6.7 & 8.1 & 5.8 to 11.0 & 3.44 & $<0.1$ \\
\hline Lying & 4.9 & 1.7 to 13.1 & 0.7 & 0.1 to 4.0 & 2.05 & NS \\
\hline Teat switching - with milk & 8.7 & 6.2 to 12.2 & 1.4 & 0.3 to 6.2 & 4.96 & $<0.05$ \\
\hline Teat switching - without milk & 78.0 & 73.6 to 81.9 & 77.5 & 66.2 to 85.9 & 0.01 & NS \\
\hline
\end{tabular}

${ }^{1}$ Data originate from direct observations during a 30 -min period immediately after milk feeding $1 \mathrm{wk}$ before weaning was initiated. Least squares means with confidence intervals (CI) are given. 
Table 3. Main effect of milk-bar design (shared or separate milk compartments) on the latency (min) from milk feeding to when the first calf was eating concentrate, hay, or lying down, as well as the maximum difference in duration of milk ingestion between calves in a group ${ }^{1}$

\begin{tabular}{|c|c|c|c|c|c|c|}
\hline \multirow[b]{2}{*}{ Latency (min) } & \multicolumn{2}{|c|}{ Separate } & \multicolumn{2}{|c|}{ Shared } & \multirow[b]{2}{*}{ F-value } & \multirow[b]{2}{*}{$P$-value } \\
\hline & Mean & $\mathrm{SE}$ & Mean & $\mathrm{SE}$ & & \\
\hline From milk - eat concentrate & 16.8 & 1.1 & 12.3 & 1.1 & $\mathrm{~F}_{1,10}=9.1$ & $<0.05$ \\
\hline From milk - eat hay & 26.4 & 4.1 & 23.3 & 4.1 & $\mathrm{~F}_{1,10}=0.3$ & NS \\
\hline From milk - lie & 26.8 & 3.4 & 29.5 & 3.4 & $\mathrm{~F}_{1,10}=0.3$ & NS \\
\hline Delta $^{2}$ duration in milk meal (min) & 2.7 & 0.6 & 0.8 & 0.6 & $\mathrm{~F}_{1,18}=4.6$ & $<0.05$ \\
\hline
\end{tabular}

${ }^{1}$ Data originate from video recordings immediately after feeding. Least squares means \pm standard error are given.

${ }^{2}$ Difference in duration of ingesting milk between the calf consuming the most and the calf consuming the least milk.

significantly affect any of the other variables recorded (Table 2 and Table 3). Observer had only an effect on the behavior licking fixture before weaning $\left(\chi^{2}=6.3, P\right.$ $<0.05$ )

Milk Intake. There was no effect of teat bar design on the difference in milk consumption between the calf consuming the most milk and the calf consuming the least milk in each group (mean milk intake per calf; separate teat bar: minimum $=1.9 \mathrm{~L} / \mathrm{meal}$, maximum $=$ $3.9 \mathrm{~L} / \mathrm{meal}$; shared teat bar: minimum $=1.9 \mathrm{~L} / \mathrm{meal}$, maximum $=4.1 \mathrm{~L} / \mathrm{meal}$ ). In groups of calves fed milk via a separate teat bar, the difference in duration of the milk meal between the calf consuming the most milk and the calf consuming the least milk was greater than in groups fed via a shared teat bar $(P<0.05$, Table 3$)$.

The residual milk from the teat bars was measured after 2 milk meals before weaning was initiated, and on average, the seperate teat bar contained $168.8 \mathrm{~mL}$ and the shared teat bar $130.5 \mathrm{~mL}$ after the calves had finished drinking.

Weight Gain. Before weaning was initiated, no effects of teat bar design, sex, or the interaction between teat bar design and sex were found on the weight gain of the calves (average $842 \pm 33 \mathrm{~g} / \mathrm{d}$ ). The variances of the weight gain for the 2 teat bars were not significantly different.

\section{During Weaning}

Effect of Teat Bar. Calves with a separate teat bar spent longer ingesting the milk $(P<0.05$, Table 4$)$ but less time performing nonnutritive sucking after the milk meal $(P<0.05$, Table 4$)$. The calves with the separate teat bar tended to spend less time sucking in total (ingesting milk and nonnutritive sucking; $P<0.1$, Table 4). No effect of teat bar design was found on time eating solid food (Table 4). Calves with a separate teat bar tended to perform more cross-sucking than calves with a shared teat bar $(P<0.1$, Table 4$)$.

Although there was still milk in the teat bar, a higher number of calves with the separate teat bar switched teats compared with calves with the shared teat bar (10 vs. 0 calves, $\chi^{2}=10.2, P<0.01$ ). The calves with the separate teat bar tended to switch teats more than calves with a shared teat bar when there was no more milk in the teat bar $(P<0.1$, Table 4$)$.

Effect of Weaning Method. From the direct observations, it was found that during weaning, WD calves spent more time ingesting the milk than WVR calves $(P<0.01$, Table 5). No effect was found on the time they spent performing nonnutritive sucking, but in total, WD calves spent more time sucking on the artificial teats than WVR

Table 4. Main effect of milk-bar design (shared or separate milk compartments) on recorded behaviors and the frequency of teat switching ${ }^{1}$

\begin{tabular}{lrrrrrrrr}
\hline & \multicolumn{2}{c}{ Separate } & & \multicolumn{2}{c}{ Shared } & & \\
\cline { 2 - 3 } Behavior (\% of observations) & Mean & CI & & Mean & CI & $\chi^{2}$ & $P$-value \\
\hline Duration of sucking & 29.6 & 26.9 to 32.4 & & 34.6 & 31.3 to 38.1 & 3.47 & $<0.1$ \\
Ingesting milk & 18.8 & 17.7 to 20.0 & & 16.9 & 16.0 to 17.9 & 4.12 & $<0.05$ \\
Nonnutritive sucking & 9.9 & 7.2 to 13.3 & & 17.1 & 13.5 to 21.4 & 4.75 & $<0.05$ \\
Eating solid feed & 12.1 & 9.4 to 15.6 & & 14.4 & 12.5 to 16.6 & 1.42 & NS \\
Cross-sucking & 4.3 & 2.7 to 6.7 & & 1.5 & 0.9 to 2.6 & 3.40 & $<0.1$ \\
Licking calf & 0.6 & 0.3 to 1.4 & & 0.7 & 0.3 to 1.7 & 0.04 & NS \\
Licking fixture & 6.7 & 5.7 to 7.9 & & 6.5 & 5.1 to 8.3 & 0.03 & NS \\
Lying & 3.4 & 1.7 to 6.8 & & 2.9 & 2.0 to 4.2 & 0.21 & NS \\
Teat switching - without milk & 74.2 & 71.7 to 76.5 & & 63.6 & 60.1 to 66.9 & 3.6 & $<0.1$ \\
\hline
\end{tabular}

${ }^{1}$ Data originate from direct observations during a 30-min period immediately after milk feeding on $\mathrm{d} 40$ (i.e., midweaning). Least squares means with confidence intervals (CI) are given. 
Table 5. Main effect of weaning method [weaning by volume reduction (WVR) or weaning by dilution (WD)] on recorded behaviors observed midweaning ${ }^{1}$

\begin{tabular}{|c|c|c|c|c|c|c|}
\hline \multirow[b]{2}{*}{ Behavior (\% of observations) } & \multicolumn{2}{|c|}{ WD } & \multicolumn{2}{|c|}{ WVR } & \multirow[b]{2}{*}{$\chi^{2}$} & \multirow[b]{2}{*}{$P$-value } \\
\hline & Mean & $\mathrm{CI}$ & Mean & $\mathrm{CI}$ & & \\
\hline \multicolumn{7}{|l|}{ Direct observations } \\
\hline Duration of sucking & 36.4 & 33.7 to 39.3 & 27.9 & 24.7 to 31.3 & 4.95 & $<0.05$ \\
\hline Ingesting milk & 24.4 & 23.1 to 25.6 & 12.8 & 12.0 to 13.6 & 7.59 & $<0.01$ \\
\hline Eating solid feed & 15.9 & 12.9 to 19.6 & 10.9 & 9.1 to 13.0 & 3.78 & $<0.1$ \\
\hline Lying & 0.8 & 0.3 to 1.8 & 12.2 & 0.7 to 20.0 & 5.50 & $<0.05$ \\
\hline \multicolumn{7}{|l|}{ Video recordings } \\
\hline Lying & 59.8 & 58.2 to 61.4 & 64.4 & 63.0 to 65.7 & 7.2 & $<0.01$ \\
\hline Standing & 31.6 & 29.8 to 33.5 & 27.9 & 25.9 to 30.1 & 3.8 & $<0.1$ \\
\hline
\end{tabular}

${ }^{1}$ Data originate from direct observations during a 30 -min period right after milk feeding and from video recordings from 0600 to $2100 \mathrm{~h}$. Least squares means with confidence intervals (CI) are given. Only variables with $P<0.1$ are shown here.

calves $(P<0.05$, Table 5). Additionally, WD calves tended to spend more time eating solid feed than WVR calves did during the 30 min after the milk was poured $(P<$ 0.1 , Table 5). The WD calves spent less time lying than WVR calves $(P<0.05$, Table 5$)$. No effect of weaning method was found on the remaining behavioral elements.

The video recording on $\mathrm{d} 6$ of gradual weaning showed that WD calves were lying for a lower percentage of observations compared with WVR calves $(P<0.01$, Table $5)$ and tended to be standing for a greater percentage of time without eating concentrate or hay $(P<0.1$, Table 5 ) during the light hours. There was no difference in the percentage of time eating solid feed between the 2 weaning methods, no effect of teat bar design, and no interaction between teat bar designs and weaning method on any of the observed behaviors during the light hours.

Midweaning ( $\mathrm{d} 40$ ), the WVR calves tended to have a longer latency for the first calf to start eating concentrate after milk feeding compared with WD calves $(P<0.1$, Table 6), and calves with the separate teat bar tended to have a lower latency to start eating concentrate after all the milk was drunk compared with calves fed with the shared teat bar $\left(2.0 \pm 0.9\right.$ vs. $5.0 \pm 0.0 \mathrm{~min}, \mathrm{~F}_{1,8}=$
5.3, $P<0.1$ ). The last day of weaning (d 44) after all the milk had been drunk, the WD calves had a shorter latency to lie down compared with the WVR calves $(P<$ 0.05 , Table 6 ). There were no effects of weaning method on the number of teat switching when there was no milk left in the milk compartment.

Interaction Between Teat Bar Design and Weaning Method. Among calves fed via a separate teat bar, the WD calves were licking the fixture $(P<0.05$, Table 7 ) and other calves less $(P<0.05$, Table 7$)$, but these calves tended to perform more cross-sucking $(P<0.1$, Table 7) than WVR calves. No other effects of the interaction between teat bar design and weaning method were found. On the last day of weaning, the calves fed milk in a shared teat bar and who were weaned by diluting the milk had the lowest latency from milk feeding to lying down (separate-WD: 25.9, separate-WVR: 23.0, shared-WD: 15.7, and shared-WVR: $25.9 \pm 2.4 \mathrm{~min}, \mathrm{~F}_{1}$, $8=7.6, P<0.05)$.

Concentrate Intake. During the weaning period, WD calves consumed less concentrate than the WVR calves $(P<0.01$, Table 6$)$. The daily concentrate intake per calf increased during the weaning period from $0.9 \pm 0.06$ to $1.8 \pm 0.06 \mathrm{~kg} / \mathrm{d}\left(\mathrm{F}_{9,72}=75.6, P<0.001\right)$. The first $2 \mathrm{~d}$ of the weaning period, there were no differences in concentrate

Table 6. Main effect of weaning method [weaning by volume reduction (WVR) or weaning by dilution (WD)] on the latency ( $\mathrm{min}$ ) from milk feeding to when the first calf was eating concentrate (d 40) and from when the teat bar was empty to when the first calf was lying down (d 44) and on the daily concentrate intake per calf ${ }^{1}$

\begin{tabular}{|c|c|c|c|c|c|c|}
\hline \multirow[b]{2}{*}{ Item } & \multicolumn{2}{|c|}{ WD } & \multicolumn{2}{|c|}{ WVR } & \multirow[b]{2}{*}{ F-value } & \multirow[b]{2}{*}{$P$-value } \\
\hline & Mean & $\mathrm{SE}$ & Mean & $\mathrm{SE}$ & & \\
\hline \multicolumn{7}{|l|}{ Latency (min) } \\
\hline From milk - eating concentrate & 8.8 & 1.2 & 12.3 & 1.2 & $\mathrm{~F}_{1,8}=4.3$ & $<0.1$ \\
\hline From empty - lying & 12.5 & 2.0 & 21.5 & 2.0 & $\mathrm{~F}_{1,8}=9.7$ & $<0.05$ \\
\hline Concentrate intake $(\mathrm{kg})$ & 1.18 & 0.07 & 1.55 & 0.07 & $\mathrm{~F}_{1.7}=14.0$ & $<0.01$ \\
\hline
\end{tabular}

${ }^{1}$ Data originate from video recordings after milk feedings. Least squares means \pm standard error are given. Only variables with $P<0.1$ are shown here. 
Table 7. Effect of interaction between milk-bar design (shared or separate milk compartments) and weaning method [weaning by volume reduction (WVR) or weaning by dilution (WD) $]^{1}$

\begin{tabular}{|c|c|c|c|c|c|c|c|c|c|c|}
\hline \multirow[b]{2}{*}{ Behavior ( $\%$ of observations) } & \multicolumn{4}{|c|}{ Separate } & \multicolumn{4}{|c|}{ Shared } & \multirow[b]{2}{*}{$\chi^{2}$} & \multirow[b]{2}{*}{$P$-value } \\
\hline & Mean & CI & Mean & CI & Mean & CI & Mean & CI & & \\
\hline Cross-sucking & 5.8 & 4.0 to 8.2 & 3.1 & 1.3 to 7.5 & 0.8 & 0.3 to 2.2 & 2.7 & 1.5 to 4.9 & 3.19 & $<0.1$ \\
\hline Licking fixture & 4.9 & 3.9 to 6.0 & 9.1 & 6.5 to 12.7 & 7.3 & 6.1 to 8.8 & 5.8 & 3.5 to 9.5 & 4.25 & $<0.05$ \\
\hline Licking calf & 0.3 & 0.06 to 1.2 & 1.4 & 0.8 to 2.5 & 1.1 & 1.0 to 1.4 & 0.4 & 0.06 to 2.5 & 4.39 & $<0.05$ \\
\hline
\end{tabular}

${ }^{1}$ Data originate from video recordings midweaning during a 30 -min period right after milk feeding. Least squares means with confidence intervals (CI) are given. Only variables with $P<0.1$ are shown here.

intake between the 2 weaning methods, but from $\mathrm{d} 3$ and onward, the WD calves consumed less concentrate than the WVR calves $\left(\mathrm{F}_{9,72}=4.6, P<0.001\right.$; Figure 3$)$. No other effects of treatment were found on the concentrate intake during weaning.

\section{After Weaning}

Concentrate Intake. The concentrate intake of the calves increased with time from d 1 to 7 after weaning $\left(2.55 \pm 0.1\right.$ vs. $2.90 \pm 0.1 \mathrm{~kg} / \mathrm{calf}$ per day, $\mathrm{F}_{6,48}=6.7, P$ $<0.001$ ), and in total, the WD calves tended to have a lower concentrate intake during the first $7 \mathrm{~d}$ after weaning compared with the WVR calves $(2.6 \pm 0.1$ vs. $3.0 \pm$ $0.1 \mathrm{~kg} / \mathrm{calf}$ per day, $\mathrm{F}_{1,8}=4.0, P<0.1$ ). There was no effect of teat bar or interaction between teat bar and weaning on the concentrate intake.
Weight Gain. From 3 d before weaning started until $1 \mathrm{wk}$ after weaning was completed, calves fed with the separate teat bar tended to have a higher weight gain compared with calves fed with the shared teat bar (24.1 \pm 1.3 vs. $20.8 \pm 1.3 \mathrm{~kg}, \mathrm{~F}_{1,38}=3.3, P<0.1$ ). No other effects were found to have affected weight gain. Neither the variances of the weight gain for the 2 teat bars nor the variances of the weight gain for the 2 weaning methods were significantly different.

\section{DISCUSSION}

Teat bars with separate milk compartments are meant to ensure that all calves receive an equal amount of milk. However, our results suggest that separate teat bars have no advantage over shared teat bars in this respect, because we found no effect of teat bar design

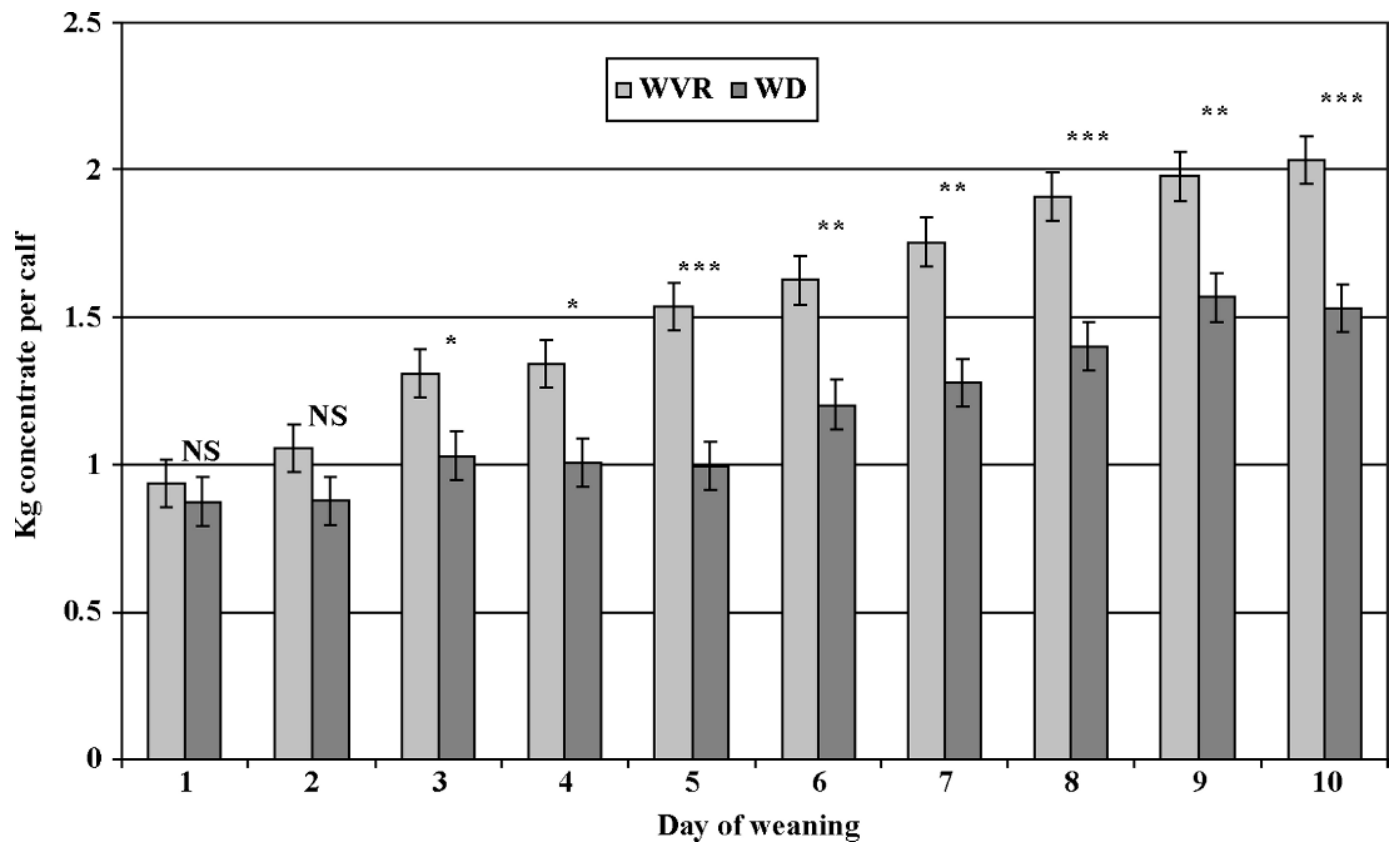

Figure 3. Least squares means \pm standard error of concentrate intake $(\mathrm{kg})$ per calf per day during weaning by volume reduction (WVR) vs. weaning by dilution (WD; $\mathrm{F}_{9,72}=4.6, P<0.001$ ). 
on the variation in milk intake within the groups. For the calves fed milk with the shared teat bar, the individual rate of ingesting milk is the sole factor that affects individual milk intake, but for the calves fed with the separate teat bar, the milk intake is also affected by the readiness of the individual calf to switch teats and its ability to displace other calves from teats connected to compartments still containing milk. This prediction is in agreement with the result that although there was still milk available in one or more teats, there was a higher number of teat switches in calves fed from a separate teat bar. The occurrence of teat switching may be a result of the calves learning that when their teat is empty there may be more milk in one of the other teats. On the other hand, the calves with the shared teat bar may have learned that when the teat is empty all the other teats are empty as well. During natural suckling, the calf typically switches between the 4 teats of the cow udder frequently, especially at the beginning and toward the end of the suckling bout (Lidfors et al., 1994). If separate teat bars, or traditional teat buckets, are used, the teat switching and competition for milk may be reduced by introducing fairly long barriers between the teats (Jensen et al., 2008). However, the results of the present experiments suggest that when teats are not separated by barriers, there is no advantage of separate milk compartments over a shared one.

We found no significant effect of teat bar design on the level of cross-sucking either before or during weaning. Even so, more teat switching during the milk-feeding period may be expected to increase the risk of crosssucking. Also, the lower amount of sucking (nutritive and nonnutritive) directed toward the teat of the calves fed via a separate teat bar during weaning may be expected to increase the risk of cross-sucking, because sucking activity may contribute to satiety in addition to providing an outlet for the sucking motivation (de Passillé and Rushen, 1997). Feeding calves via a teat appears to be the most important factor in reducing cross-sucking, as also suggested by Loberg and Lidfors (2001) and Jensen (2003). However, in the studies investigating cross-sucking, a low level of this abnormal behavior is often seen (Veissier et al., 1998; de Passillé et al., 2004), and more studies are needed to investigate how to reduce it further, or eliminate it, among calves fed via a teat.

The lower latency from milk feeding to when the first calf was eating concentrate in the groups with shared teat bars may be due to these calves all finishing ingesting milk at the same time. Thus, they may have turned to the concentrate at the same time, and they may have stimulated each other to eat more concentrate. On the other hand, the calves fed with the separate teat bar may have been reluctant to direct their attention to- ward the concentrate while other calves in the group were still ingesting milk.

Weaning method significantly influenced the behavior of calves. The WVR calves appeared calmer because they were lying more, although they had a longer latency to lie down after finishing milk. Gradually reducing the milk encourages the calves to increase their concentrate intake during weaning compared with abrupt weaning (Nielsen et al., 2008). The finding in the present study that concentrate intake is less for the WD calves suggests that WD calves react less to being gradually weaned. This is supported by Jasper et al. (2007), who found that WD calves reacted very little behaviorally to this. In the study of Jasper et al. (2007), WD calves did increase their concentrate intake as compared with nonweaned calves, but in the present study, the WD calves did not reach the same level of concentrate intake during weaning as the WVR calves. In their review, Weary et al. (2007) suggest that weaning distress can be reduced if the calves increase their intake of solid feed before weaning and thereby reduce their dependency of milk. Our data suggest that the preferable weaning method is WVR over a long period because of the higher concentrate intake during and after weaning and because of the higher percentage of lying during the weaning period shown by the WVR calves.

\section{CONCLUSIONS}

In conclusion, the present study shows that during the milk-feeding period, a separate teat bar increases the teat switching, the variation in meal duration within the group, and the latency to eat concentrates after milk ingestion. Furthermore, weaning by diluting the milk causes more sucking on teats but less lying and a lower consumption of concentrates. The lower consumption of concentrates was also evident after weaning.

\section{ACKNOWLEDGMENTS}

John Misa Obidah and Erik Luc Decker (University of Aarhus) are acknowledged for their help with observations, weighing, and data editing. We thank the farm personnel at Research Centre Foulum, University of Aarhus, for the daily management of the animals throughout this experiment. Ulrich Halekoh (University of Aarhus) and Tomas Thierfelder (Swedish University of Agricultural Sciences) are acknowledged for their statistical support. This experiment was funded by the University of Aarhus, Faculty of Agricultural Sciences, Department of Animal Health, Welfare and Nutrition. We thank Birte Lindstrøm Nielsen (University of Aarhus) for comments on the manuscript. 


\section{REFERENCES}

de Passillé, A. M., and J. Rushen. 1997. Motivational and physiological analysis of the causes and consequences of non-nutritive sucking by calves. Appl. Anim. Behav. Sci. 53:15-31.

de Passillé, A. M., and J. Rushen. 2006. Calves' behaviour during nursing is affected by feeding motivation and milk availability. Appl. Anim. Behav. Sci. 101:264-275.

de Passillé, A. M., J. Rushen, and D. M. Weary. 2004. Designing good environments and management for calves. Adv. Dairy Technol. 16:75-89.

Jasper, J., M. Budzynska, and D. M. Weary. 2007. Weaning distress in dairy calves: Acute behavioural responses by limit-fed calves. Appl. Anim. Behav. Sci. doi:10.1016/j.applanim.2007.03.017.

Jensen, M. B. 2003. The effects of feeding method, milk allowance and social factors on milk feeding behaviour and cross-sucking in group housed dairy calves. Appl. Anim. Behav. Sci. 80:191-206.

Jensen, M. B. 2006. Computer-controlled milk feeding of grouphoused calves: The effect of milk allowance and weaning type. J. Dairy Sci. 89:201-206.

Jensen, M. B., and M. Budde. 2006. The effects of milk feeding method and group size on feeding behavior and cross-sucking in grouphoused dairy calves. J. Dairy Sci. 89:4778-4783.

Jensen, M. B., A. M. de Passillé, M. A. G. von Keyserlingk, and J. Rushen. 2008. A barrier can reduce competition over teats in pair-housed milk-fed calves. J. Dairy Sci. 91:1607-1613.
Jung, J., and L. Lidfors. 2001. Effects of amount of milk, milk flow and access to a rubber teat on cross-sucking and non-nutritive sucking in dairy calves. Appl. Anim. Behav. Sci. 72:201-213.

Keil, N. M., and W. Langhans. 2001. The development of intersucking in dairy calves around weaning. Appl. Anim. Behav. Sci. 72:295-308.

Lidfors, L. M., P. Jensen, and B. Algers. 1994. Suckling in freeranging beef-cattle - Temporal patterning of suckling bouts and effects of age and sex. Ethology 98:321-332.

Littell, R. C., G. A. Milliken, W. W. Stroup, and R. D. Wolfinger. 1996. SAS ${ }^{\circledR}$ System for Mixed Models. SAS Inst. Inc.,Cary, NC.

Loberg, J., and L. Lidfors. 2001. Effect of milkflow rate and presence of a floating nipple on abnormal sucking between dairy calves. Appl. Anim. Behav. Sci. 72:189-199.

Nielsen, P. P., M. B. Jensen, and L. Lidfors. 2008. Milk allowance and weaning method affect the use of a computer controlled milk feeder and the development of cross-sucking in dairy calves. Appl. Anim. Behav. Sci. 109:222-236.

Olsson, U. 2002. Generalized Linear Models. An Applied Approach. Studentlitteratur, Lund, Sweden.

Rushen, J., and A. M. de Passillé. 1995. The motivation of non-nutritive sucking in calves, Bos taurus. Anim. Behav. 49:1503-1510.

Veissier, I., A. R. Ramirez de la Feb, and P. Pradelc. 1998. Nonnutritive oral activities and stress responses of veal calves in relation to feeding and housing conditions. Appl. Anim. Behav. Sci. 57:35-49.

Weary, D. M., J. Jasper, and M. J. Hotzel. 2007. Understanding weaning distress. Appl. Anim. Behav. Sci. doi:10.1016/j.applanim.2007.03.025. 